\title{
Approaching mythology in the history curriculum of compulsory education in Greece
}

\author{
Maria Vlachaki* - University of Thessaly, Greece \\ George Kokkinos and Zeta Papandreou - University of the Aegean, Greece
}

\begin{abstract}
Myth can be a first step in historicizing the past and at the same time in appreciating ancient cultures and developing the essential skill of empathy. A main objective of the history curriculum for the third grade of primary school in Greece is for children at 8 and 9 years old to familiarize themselves with the basic cultural elements of the origins of Greek, European and global civilization. Ancient Greek myths are taught using references and links to the myths of other peoples and cultures, and by identifying similarities and differences in the interpretation of the world within the framework of a multi-perspective, intercultural approach. Myths also depict the relationship between man and nature. They constitute man's attempt to interpret the physical and social environment. In addition, myths present the relationship between man and the divine in the early stages of cultural evolution, and at the same time provide evidence of the culture of a historical period. Pupils become aware of the fact that myths used to have a symbolic and ritualistic function, which aimed to initiate younger members into the acceptable practices and values of their community. Myths provided meaningful models of action (exempla) through their allegorical nature. Moreover, myths facilitate the analysis of human behaviour by introducing the schema of cause and effect. Mythical thought seeks to understand causality, which is also the primary aim of science. In this sense, mythical discourse is connected to scientific discourse. Within the framework of a methodological approach based on these theoretical assumptions, this paper also includes a presentation of educational activities and pupils' perceptions as part of a survey conducted in a third-grade primary school class in Greece.
\end{abstract}

Keywords: Greece; Greek history curriculum; Greek myths; identity; mythology: other peoples'; myths: symbolic; values

\section{Introduction: Interpreting the myth}

The creation of myths is an anthropological constant that has occurred in all societies and civilizations. Even in our day, mythification is a latent but structural characteristic of the human intellect and spirituality, which is still linked primarily to metaphysics, art, religion and folklore. Myths do not represent deficient or 'flawed' thinking. They encompass traces of objective observation, truth and rationalism, and they can be traced back to prehistoric societies. They usually pertain to a 'sacred narrative', which refers to the historical and cultural specificities of every social form. Thanks to their regulatory, quasi-religious character, myths are an object of respect in a community, and people are required to adapt to and internalize their messages.

In the early stages of the development of civilization, myths responded to the existential insecurity of archaic humans: they played a dominant (if not exclusive) 
role in the attempt to explain the creation of the world, and the relation of man to the divine, nature, animals and heroes. However, beyond their explanatory function, myths also serve as a safeguard for social cohesion, establishing mechanisms of social reproduction by acting in an exemplary, humbling, didactic and socializing manner. In addition, myths mediate and reconcile contradictory trends within a society (LéviStrauss, 1978; Kirk, 1974).

Myths belong to the sphere of the imagination, and are built on opposing concepts, thus creating bipolar entities that cannot be bridged. They serve to reveal the invisible forces that govern the universe and designate power within human society. They interpret diverse social and natural phenomena (Lang, 1887), and perceive the world in a dynamic rather than a static form, as an evolving, yet eternally repeated drama. Myths are the progeny of a society, echoing its values. Over time they may be transformed, but they never lose their semantic-symbolic core meaning.

There are three main approaches to interpreting myth:

(1) The functional theory, which organically connects myths to the natural and social environment and establishes a kind of social charter of perceptions and habits within society (Malinowski, cited in Karakantza, 2004: 199).

(2) The psychoanalytic theory, which views myths as mental formations that arise from the relationship between the conscious, subconscious and unconscious, such as frustrated desires and fears on a collective level (Freud, 1991), or as archetypes, global mental predispositions, or models that pre-exist in nature (Jung, cited in Stevens, 2006).

(3) The structural theory, which uses myths as symbolic mental hubs, in order to facilitate the mapping of the unified structure of human language and thought. According to Lévi-Strauss (1963), myths operate as logical models that function as mediators between the diverse oppositions to be found within society.

Ancient Greek myths in particular are viewed as 'cultural tools' (Wertsch, 2002). Through them, cultural archetypes have developed over time, along with geographical frameworks and boundaries of a symbolic nature, and centuries-old 'technologies' of cultural memory (ancient Greece/Hellenistic world/Renaissance) (Buxton, 2002). This cultural memory then in turn embodies part of the identity of the Western world itself, as well as specific national identities, such as those of Greece and Italy (Aeneas, for example). The myths of ancient Greece turn the 'grammar' of Western civilization into symbols, become ecumenical, and constitute exemplary meanings channelled through aesthetic codes within the framework of visual arts (painting, sculpture), theatre and literature (James Joyce's Ulysses, for example). The exemplary quality of the meanings is the mechanism by which historicity is lifted, and time is perpetually flowing and fossilized, to the point that it directly refers to a form of exemplary historical consciousness (Koselleck et al., 1982).

\section{The use of myths in education}

Within Greek national consciousness and official historiographical standards, as shaped to a great extent by The History of the Hellenic Nation (1860) of Konstantinos Paparrigopoulos, there has been a tendency to view the creation of the twelve Olympian gods and of ancient Greek myths, as well as Homer's works, 'as documenting narratives ... [about] the most distant past'. This is despite the fact that Paparrigopoulos himself made a distinction between the historical and mythical past, and regarded the first Olympiad (776 BC) as the start date for the history of ancient Greece. The distinction 
between mythology and history was common ground in later books written by Greek positivist historians, such as the works of Spyridon Lambros and Pavlos Karolidis, in which myths are attributed the role of 'symbolic texts' (Karamanolakis, 2018: 665, 670).

It is reasonable to state that the presentation and analysis of the myths selected to form part of the curriculum in the third grade of primary school, for children aged 8-9 years, must be carried out bearing in mind the distinction between mythology and history, given that myth and historical reality are different. Myth reflects the relationships between man, nature and the divine in the early stages of cultural evolution, and at the same time testifies to the cultural characteristics of a period, rather than simply providing a symbolic depiction of historical facts. This observation renders myths as carriers of historical concepts and, from this point of view, can form an initial basis to historicize the past, avert the downgrading of ancient civilizations and nurture the critical skills of historical empathy and imagination.

Imagination is a primary mental skill. It constitutes a creative force that leads to understanding. It feeds on and develops through storytelling (Fines, 2002: 70). For this reason, storytelling/narration can serve as an extremely useful mental exercise for the formulation of our mental map. Its importance becomes even more pronounced when the narration of stories involves remote worlds and the distant past. More specifically, where mythology is concerned, imagination is characterized by the emergence of hidden, latent or 'invisible' aspects and relationships. 'It is related to images and symbols, and helps us dive into new worlds and give shape and form to the elements that comprise them. It becomes a driving force for empathy, mainly of a historical nature' (ibid.: 63).

Although a child's mind cannot possess the maturity of mind of 'a poet, a novelist and an inventor', it can nevertheless follow the same orbit and use relevant techniques (ibid.: 64). More specifically, children have by nature the ability to express, through their imagination, free and unconventional explanatory proposals or alternative hypotheses (ibid.). In order for imagination to operate within the framework of historical learning, a stable foundation and focus are required. There are two kinds of imagination: descriptive-representational-static (ibid.) imagination, and narrative-explanatorydynamic imagination, which promotes understanding and does not stop at the facts, but rather attempts to provide explanations, follow their impact and attribute meaning to them. The mechanisms of rational understanding comprise one pillar of imagination, while empathy accounts for the other. Both of these kinds of imagination are necessary in our search for historical understanding and in the composition of historical thought; they are intertwined and interconnected (ibid.: 65).

Historical understanding is the result of four successive steps: (1) description; (2) transition to proportionality (categorization, classification, hierarchical order); (3) transition to metaphor (individual understanding and empathy); and (4) symbolization. Historical thought presupposes the existence of: (1) event-based knowledge; (2) a range of experiences regarding the human condition and behaviour; (3) a number of skills focusing on inductive reasoning and the methodical organization of research; and (4) historical imagination. All of the above are also related to a person's thirst for knowledge and interest in the past, and to the motivation provided and the value for a society or learning community of methodically delving into the past (ibid.: 66).

When pupils study myths from this perspective, they gradually begin to acquire a genetic historical consciousness. With regard to history courses, historical thought - whose attributes include the multidimensional, critical and reflective approach of modern historical discourse - primarily involves critical thinking and is based on the cultivation of mental and psychological skills, such as analytical and synthetic abilities, 
the establishment of the causality that links events to each other, the disclosure of the values and incentives that guided the actions of individuals and groups, an understanding of the historical significance of facts and phenomena, and multifaceted historical empathy. For the formulation of critical thinking, the concept of adopting a historical perspective plays an important role. More specifically, historical time can be viewed as a continuum, since many things survive from the past into the present, although the past still remains 'a foreign country', which is why it is extremely difficult to understand. This argument becomes even more complicated if we take into account: (1) the various epistemological and ideological viewpoints that are found at the heart of the historical questions asked of the past by the present; and (2) the fact that what we have inherited from the past has been unavoidably infiltrated both by competing sociopolitical interests and diverging historical occurrences (space of experience) and by the expectations, uncertainties or fears that the future creates for each group (horizon of expectation). Acknowledging the diverse nature of the past is a major challenge for pupils. Nevertheless, their response to this challenge sheds light on the broad spectrum of human behaviours, beliefs, views and social organizational models. It offers alternative interpretations to established and conventional knowledge, and broadens the horizons of thought by providing a historical meaning to the way in which we perceive current conditions and events (theoretical framework of history curricula in primary and secondary education, third grade of primary school to second grade of upper secondary school (Lykeio), aims of history lessons). Historical narratives are particularly useful when they familiarize children with cultural otherness and with the 'foreignness' of the past, when they contribute to broadening their horizons and enriching their representations and experiences, when they serve as emotional stimuli and lead to identification with real or mythical characters, when they bring to light alternative viewpoints that contribute to a multi-perspectival consideration of the past and, finally, when they articulate and condense long-term cultural memory and tradition (Solé et al., 2016: 137-54).

Within this framework, it is clear that we should pay particular attention to the ritualistic and functional interpretation of myths (concerning, for example, periodic death and rebirth, decay and resurrection, the natural circle of life, fertility and purgation, relation of myth to metaphysical anxiety, religion and the quest for reasonable explanations for natural phenomena). The promotion of the psychoanalytic and semantic dimensions of myths - despite their vital significance as cultural metacognitive codes for understanding speech, thanks to ancient Greek tragedy and comedy - if deemed necessary, will be a secondary goal, due to children's inability at this age to comprehend complex relationships, complicated terms and abstract theoretical discourse.

The educational character of mythology is therefore related to children's familiarization with the cultural grammar of the origins of Greek, European and global civilization, as well as the knowledge that, in all civilizations, mythical narratives have served as symbolic dramatizations and symbolic systems with a rationalizing focus, referring to rituals that respond to social needs and express social processes, such as the resolution of conflict. In their heyday, myths aimed at initiating younger members into the values and practices of their society, by functioning as a mechanism for the internalization and reproduction of relations, and for ensuring the social cohesion of the group. These are relationships that have changed over time, however. The stories used as learning material in the early stages of socialization at school must be short, concise and straightforward, with a beginning, middle and end. They must be based on situational conflict, belong to a discernible context, contain shifts and turning points of 
decisive importance, prepare the reader for developments in the plot but also surprise him/her, provide incentives and create interest, reframe and challenge events and situations, produce a symbolic meaning and impart a moral message (Fines, 2002: 75-6). Mythology meets almost all of these requirements.

Furthermore, in order to develop a more flexible history curriculum, which acknowledges and includes cultural differences (Council of Europe, 2018), the teaching of ancient Greek myths must include brief references, comparisons and connections to the myths of other peoples and civilizations, where this is feasible. Thus, on the one hand, the ecumenical nature and common anthropological origins of mythification and symbolization are understood, while, on the other hand, the relevant cultural specificities are explained according to the principles of a more intercultural approach to mythology. They must not be exclusively or primarily connected to the political, military, ideological and cultural processes of prehistoric societies. On the contrary, the following assumptions must be taken into account:

(1) Myths constitute an attempt by humans to interpret their natural and social surroundings, and are used by them to attribute meaning to the world in which they live. The material of myths has been constantly transformed in the hands of society's key actors, as people (specifically religious authorities and scholars) in both the past and the present have tried to redefine their position within a fluid natural/environmental, social and political framework, and to provide (new) answers to questions that still remain unresolved. Ancient Greek myths only ceased to play a functional role in society during the Hellenistic period; they became established and 'fossilized', and gradually transformed into mythology through their collection, recording and classification as part of a cultural legacy.

(2) What stands out among the mythical types of the classical era are the habits of primeval man: emotional reactions to natural phenomena, human efforts to tame the natural environment, the hunter's instinct, initiation rituals and so on.

(3) Moreover, through their moral function, myths also embody the value system governing human behaviour, providing tangible examples of what people should or should not do. In other words, they serve as exempla, according to which human behaviour is judged and evaluated (Karakantza, 2004: 47). Furthermore, they do not only function as educational models, but also analyse human behaviour by introducing the element of causality.

(4) Mythical thought is concerned with causality, meaning the quest for reasons and causal sequence, which also constitutes a primary goal of science. In this sense, mythical discourse is genetically connected to scientific discourse, the former forming the matrix of the latter. It also has ties to philosophy, since mythos is embedded in logos and vice versa. After all, two basic forms of argumentation analogical and antithetical reasoning - are categories of thought that were already well-established in their mythical predecessors.

(5) More specifically, for ancient Greeks, myths represented their oldest history; this can be discerned from the fact that Thucydides passes judgement on Homer when referring to the work of former historiographers and poets, while the lonian scholars (for example, Hecataeus of Miletus) looked for the most rational variant of myths among the lineages of mythical heroes (Buxton, 2002).

\section{The goals of a curriculum incorporating mythology}

According to the proposal in the framework of the new curricula for history classes in Greek compulsory education in 2018, the goals of the curriculum for mythology 
were shaped on the basis of children's age, interests, and mental and perceptual skills. Furthermore, the processing of myths approximates the intellectual functioning of children, who display an ability to create stories from a very early age. It seems, therefore, that the mental age of children functions along the lines of a 'positive orality'. In societies where there is no written word, the narration of myths/stories functions as a 'practical test of reality'. The intellectual life of humans is organized on this basis, and experiences evolve into living memories, using techniques such as rhythm, metre, form and history. We come across similar properties in the oral culture of childhood all over the Western world, especially in fairy tales. The content of fairy tales is based on strong abstract concepts that children already own, the leading characters are as weird as those found in myths, the structure of fairy tales themselves is based on primary oppositions, while intermediate concepts are gradually addressed (for example, cold/ hot, warm/cool and life/death, and fairies, ghosts and elves).

Both in stories and in myths, the concept of metaphor plays a catalytic role (Egan, 1986: 2-26). After all, the ecumenical nature of mythical language or mythological thought, which is inhabited by gods (resembling humans, terrible beasts or both) (Danesi, 2017: 165), heroes and otherworldly creatures (ibid.: 163), has led several researchers to view the creation of myths as a transhistorical and intercultural constant, resulting from a sort of 'narrative instinct'. It is as if the cultural process itself, which provides a meaning to the world with content, purpose and values, cannot be explained outside a narrative context, and through the co-articulation and juxtaposition of genealogies and 'founding narratives'. The latter, despite the different historical contexts to which they belong, generally follow the same syntactic structure and the same poetic logic. As noted by Claude Lévi-Strauss, they address binary oppositions: god/human, good/evil, divine/demonic, right/wrong, father/mother, female/male, order/disorder, life/death, union/dissolution, day/night, heaven/hell (Danesi, 2017: 166). In other words, they comprise 'metaphysical cognitive systems', which explain both the origin of beings and the human course through time, as well as the creation of the universe (cosmological myths) and natural phenomena (explanatory myths) (ibid.: 163), while occasionally even reaching the point of describing and foreshadowing disaster (eschatological myths) (ibid.: 164), thus presaging - indirectly but clearly - the continuous rebirth of nature. Therefore, the cultural utility of myths, and the educational and moral gain they offer, involves the identification of the heterogeneous ways in which different societies, mainly of ancient times, 'have answered the basic questions concerning the world and the human position within this world' (ibid.: 164), pertaining mainly to their particular features and any convergences or radical deviations.

Consequently, the study of myths, even at the stage of early socialization within a school environment, can motivate the primary historical interest of children regarding what we could refer to in the language of historical ecology as the 'biodiversity' of human groups and civilizations. The incitement of historical empathy in this case is not to be taken lightly. At the same time, however, a secondary historical interest may also be activated, which is related to the ability to decode the semiotic codes that comprise the background and framework of the symbolic languages used in visual and plastic arts, architecture, theatre, music, literature, cinema, and even fashion and advertising (ibid.). In general, without the possibility of accessing, even from childhood, the 'weft of early myths' (ibid.: 166), the symbolic language of Western civilization (mainly since the Renaissance) emerges as cryptic and hermetic, if not incomprehensible (ibid.: 33 ).

According to the proposal in the curriculum, the teaching units should include (see Figure 1): 
(1) Introduction. A distinction is made between history and myth, along with an effort to search for elements of historical truth in myths.

(2) Cosmology. This is examined with the realization that humans in the distant past were not inferior to us, and used myths in order to explain the origins of the world and to find suitable ways to organize their societies. In this way, the framework is also created to perceive, on the one hand, the universal need to understand the world, particularly during periods of geological disruption or natural disasters, and, on the other hand, the fact that the creation of myths is linked to all past civilizations; mythification is a common characteristic of all human societies.

(3) Relationship to the divine. This unit aims at familiarizing pupils with myths related to the twelve ancient gods of Greece or smaller groups of deities, as well as myths that concern the existence of relevant deities and cultural and religious traditions of other peoples, so that pupils are able to make comparisons. In addition, the unit aims to help children understand that unfulfilled human passions and behaviours are projected on to the gods ('humanification' of the divine).

(4) Relationship with nature. This unit is connected to cultural development and human evolution, as recorded through myths. In this case, the goal of teaching is to identify and classify - by considering specific myths - the knowledge conveyed to people about fauna and flora, fertility and land cultivation, natural phenomena, constellations, geological formations and the renewal of nature.

(5) Heroic mythology. The leading roles are played by Heracles, Theseus, Ulysses, as well as collective actions, such as the journey of the Argonauts and the Trojan War.

(6) Archetypal myths. This unit is predominantly concerned with ancient Greek myths that promote specific regulatory standards and values, such as justice, freedom, the value of common sense and knowing how far one can go, the wish to be recognized, intelligence and ingenuity, as well as with myths with a similar subject matter that originate from other peoples. Within this concluding unit, it is appropriate to seek and discuss similarities, analogies, and points of convergence and deviation, regarding the social standards and values that are depicted in the myths of various peoples. Some of the emblematic protagonists of these myths include Daedalus and Icarus, Orpheus, and Thor.

The proposal for a didactic use of mythology is founded on the need to comprehend and mentally process primary and secondary historical concepts (Repousi, 2004: 332-3; Kokkinos, 2003: 229-305). The primary historical terms, which are closely linked to the past and its traces, express the way in which historical subjects themselves perceived historical phenomena. Primary historical concepts, such as mythology, symbol, gods, mortals, creation of the world, power, hero, demigod, campaign, siege, human sacrifice and oracles, all help pupils understand the units they are working on, through predetermined ways of deciphering the world, actions and reactions. However, the inclusion of these concepts within a broader framework, such as the one involving secondary historical concepts, is viewed as an essential supplement in the curriculum. Secondary historical concepts are those formulated by later societies in order to express aspects of the historical phenomena under examination. More specifically, in our proposal, pupils savour the charm of myths through narratives and activities, and gradually examine in depth various terms such as fact, myth, historical truth, history, historical sources, change, time sequence, empathy, cause-effect relationships, consequences, change, cultural evolution and alternative interpretations. 


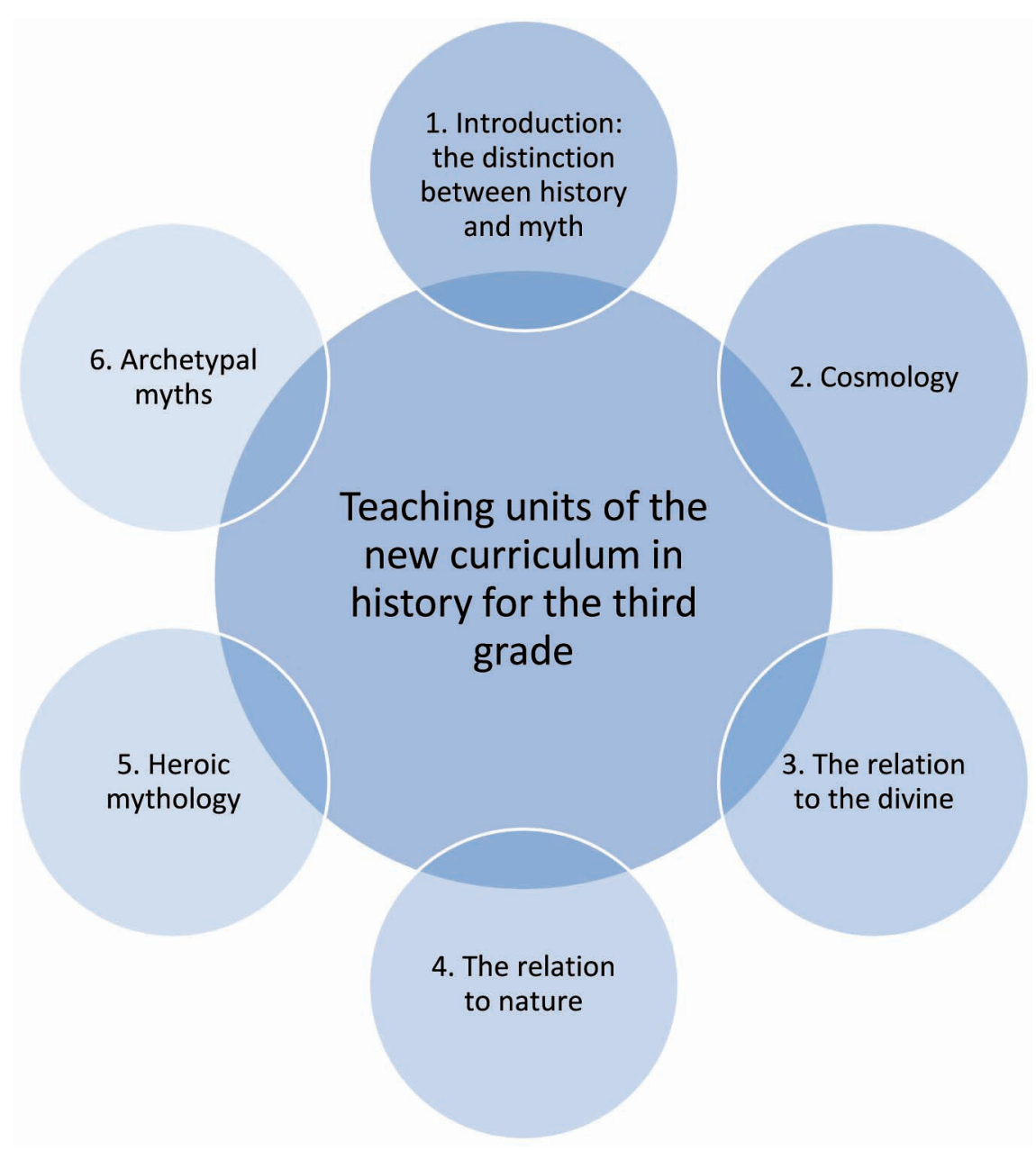

Figure 1: Teaching units of the new curriculum in history for the third grade

An indicative presentation of the educational activities and proposals for the evaluation of the curriculum, which combines the familiarization of pupils with the magic of myth, the cultivation of historical empathy, and a critical search for their sources, includes the following elements (see Figure 2):

(1) Multi-modality - valorization of diverse sources

Educational activities that serve this objective include:

- Reading myths from a variety of sources, narrating them in class and finding their common elements and differences.

- Correlating myths with figurative sources, such as representations on pottery and sculpture.

- Acquaintance, presentation and justification of the symbol for each of the twelve gods of Olympus through figurative sources - archaeological findings.

(2) Intercultural approach

Educational activities that serve this objective include:

- Comparing perceptions of the world's creation, according to the mythology, cosmology and religion of various peoples. 
- Identifying relevant myths from global mythology that portray the relationship between human sacrifice and the appeasement of gods in various religions and cultures.

(3) The relationship of man to nature and its interpretation

Educational activities that serve this objective include:

- Comparing myths in order to identify references to plants and animals, the ways in which the earth bears fruit and how nature is reborn, natural phenomena and constellations, and discussing man's relationship to nature.

- Writing short essays on scientific ideas that are related to, or have emerged from, myths linked to natural phenomena.

- Putting pupils in the position of the hero and inventing ways to resolve a tough situation (for example, dealing with Scylla and Charybdis).

- Simulating conflicts (Titanomachy, Gigantomachy) through the use of audiovisual material (storms, hurricanes, floods, stormy seas, volcanic activity and earthquakes).

- Creating and solving crosswords, word searches and acrostics, on subjects drawn from myths and their relevant scientific explanations.

(4) Historical empathy - historical imagination

Educational activities that serve this objective include:

- Dramatization of scenes referring to myths and role-playing mythical figures.

- Dramatization and presentation of the feelings and thoughts of heroes using techniques, such as the technique of the 'conscience alley' or 'inner voices' regarding the decision to sacrifice Iphigenia.

- Dramatization based on making up imaginary scenarios, where a difficult situation is resolved through the sudden intervention of a god ('deus ex machina').

- Creating comics using special software on topics such as the journey of the Argonauts, the Odyssey and the lliad.

- Making constructions (for example, a model of the raft of Ulysses or the Trojan Horse) and drawings depicting mythical scenes.

(5) Studying historical concepts in depth (myth, fact, causes, impact, change, alternative interpretations)

Educational activities that serve this objective include:

- Creating a semantic map through mapping software representing pupils' views on the interpretation of a myth.

- Discussion on the decision of the Achaeans to campaign against Troy.

- Dramatization of the confrontation between Prometheus and man, and similarly between Zeus and Prometheus and man, by using arguments in favour of giving fire to mankind.

- Presenting and discussing films with mythological subjects in class.

- Observing the depiction of mythical scenes on pottery and in sculpture. 


\section{(1) Multi-modality - valorization of diverse sources}

(2) Intercultural approach

(3) The relationship of man to nature and its interpretation

(4) Historical empathy - historical imagination

(5) Studying historical concepts in depth

Figure 2: The main goals of the proposed educational activities

Among primeval agricultural peoples, where the preservation of life was largely dependent on meteorological phenomena, emotional imagination played a leading role, since it is a dominant feature of the primitive psyche. This resulted in phenomena being explained as a result of the actions of beneficial or hostile powers (Diel, 1980: 11). However, it is very important that myths are not only connected to matters of survival or concerns of a purely utilitarian origin. Imagination should not only be viewed as emotional and undefined; it is also expressive and symbolic. The battle between divine powers, in combination with human activity, heroic action, the fulfilment and sublimation of goals (as rewarded by the gods), express thoughts that are projected at a metaphysical level, but also constitute activities that are filtered on a moral level. Intrapsychic human conflicts should not only be linked to the mythical depictions of stars and their rotational movement, and their meaning in relation to daily survival, but also to symbolisms that concern human beings and express their actual fate (Diel, 1980: 12-13). Anthropological research has shown that 'we do not act because we know; but we know because we are destined for action' (Fichte, 1954: 142).

The position of man in the world is defined by three axes: work, symbolism and exchange. Since the discovery of tools, humans have had the possibility to dynamically intervene in the transformation of their environment. Symbolic systems, dominated by language, have facilitated their intervention in nature. Exchanges have further accelerated this interference, by signalling geographical dispersion and the development of society's organization (Dimitriou, 2017: 25-6). Gradually, the 'biological transformations' linked to human activity in the world have been enveloped in myths. This change in social relationships, suffering and disease were all potentially linked to an attack from evil spirits in the case of animism (primeval religion) or, in the case of religion, to the wrath of god and divine justice (Dimitriou, 2017: 108).

The activities proposed in the curriculum aim primarily: (1) to encourage pupils to approach ancient cultures through a mythological explanation about natural phenomena and the world; and (2) to help pupils understand the need for myths and 
the mechanisms used to construct them. On a second level, the aim is for pupils to perceive the meaning of the 'synchronicity of the asynchronous', that is that various systems of viewing the world (such as mythology and science) may co-exist during the same historical period.

\section{The experimental implementation of the proposal in class}

Aimed at highlighting pupils' response to this new methodological proposal, as described above, along with any difficulties and concerns regarding its implementation, certain educational activities were followed experimentally as a case study in a thirdgrade class of the 23rd Primary School of Kalamaria in Thessaloniki, a town in northern Greece. Twenty-five pupils aged 8 to 9 years attended this class during the academic year 2017/18.

In order to record the knowledge, views and interpretations of the pupils, a structured questionnaire was used containing open-type questions:

(1) What were the reasons behind the Trojan War?

(2) In your opinion, was the Trojan War a myth or fact?

(3) How do you evaluate Iphigenia's sacrifice?

(4) What is Hector's advice to his son Astyanax?

(5) What characteristics were common to ancient Greek heroes?

(6) Which hero would you like to resemble and why?

(7) What characteristics make a hero in today's world?

(8) What were Scylla and Charybdis in Greek mythology and what did they symbolize?

As an additional research technique, and an educational activity on Scylla and Charybdis at the same time, pupils made drawings inspired by the myths they were taught. Their drawings were used to examine whether the pupils understood the meaning of the myths and whether they tried to provide an explanation for the heroes' actions.

The questionnaire was handed out at the end of the academic year. It was part of the evaluation of the educational process, which was carried out both during (formative assessment) and at the end of (summative assessment) the school year. The first part of the questionnaire included personal details, such as full name and gender, and the class to which each pupil belonged. In addition, data from the school records were used concerning the specific ethno-cultural and religious identity of each child. The second part of the questionnaire included eight main open-type questions, covering the basic assumptions - the questions of the present study.

The aim of the first question ('What were the reasons behind the Trojan War?') and the second question ('In your opinion, was the Trojan War a myth or fact?') was to highlight whether pupils can discern the causes and the historical truth linked to the myths described. It was accepted from the beginning that mythos runs alongside logos and the reverse. This is what Nestle (1999: 21) and Vernant (2001 in Karakantza, 2004: 47) refer to as the 'interpenetration of Logos and Mythos'.

The aim of the third question ('How do you evaluate Iphigenia's sacrifice?') the fourth question ('What is Hector's advice to his son Astyanax?') and the fifth question ('What characteristics were common to ancient Greek heroes ?') was to examine whether the pupils empathetically assimilate the values and comprehend the motives that govern the behaviour of the actors. Furthermore, the aim of the sixth question ('Which hero would you like to resemble and why?') and the seventh question ('What characteristics make a hero in today's world?') was to examine whether pupils are in 
a position to perceive the moral standards in force within the historical and cultural framework that has created them.

Finally, the purpose of the eighth question ('What were Scylla and Charybdis and what did they symbolize?') was to record whether pupils correlate myths with the interpretation of natural phenomena and with changes they observe in the environment (for example, how seasons change, the cycle of day and night, changes to the weather).

The same questionnaire was also given to a group of 25 pupils, aged 8-9 years, from another class at the same school, which was used as a control group. In the control group, myths were presented as being the complete opposite of history, something that is not real but imaginary. The pupils were therefore not taught that myths may potentially contain elements of logos, and of historical truth, according to the view that 'forms of mythos exist within logos and also forms of logos can be found in mythos' (Nestle, 1999: 21; Vernant, 2001 in Karakantza, 2004: 47). Subsequently, the related educational activities served the purposes of a primarily knowledge-centred approach and the achievement of predefined academic goals, according to the current history curriculum. Narration constituted the main didactic method according to this rather traditional, knowledge-centred approach to myths, and the textbook was the only historical source used. On the other hand, the development of experiential activities that could potentially encourage the active participation of pupils, the valorization of a remarkable wealth of knowledge and experiences and the formulation of alternative interpretations of the myths, within the framework of a 'learner-centred' approach, was limited. Along these lines, pupils were not motivated to understand the meaning of myths within the historical context in which they were created, and also within a broader history and culture, according to a 'society-based' approach. However, Ellis (2010) has noted that these three approaches - knowledge-centred, learner=centred and society-based - are equally important for the effective teaching of social studies.

The first group of pupils were exposed to a different methodological perspective, according to the new history curriculum, whose aims include:

(1) Formulating alternative interpretations and assumptions by introducing the terms 'allegorical' and 'symbolic'. Symbolism encompasses a complementary duality that explains its ambivalence: each symbol is open to two opposing interpretations that need to be joined together for its full meaning to be understood (Benoist, 1992: 53-4).

(2) Encouraging the increased value of pupils' cultural and educational capital within the framework of a constructive approach to the understanding of myths and the discussion of alternative views.

(3) Familiarization with the use of various material sources/findings from the past, when formulating concepts (for example, representations on pottery (see Figure 3), burial offerings, weapons, bronze armour) and the creation of representational drawings and artwork according to a multi-perspective, crosscurricular approach (Rowley and Cooper, 2009).

(4) Discovering the time and space frame behind the myth and their portrayal (in timelines and maps respectively). Those taking part in the Trojan War were wellknown kings of certain cities that still exist today.

(5) A comparative view of the present and the past, by examining the different motives, causes and consequences of the actors' actions.

(6) Developing cultural empathy by understanding and dramatizing the particular values, habits, customs and roles present during the different periods and societies in which the myths evolve (the hero as a role model for boys, the position 
of women, for example the cases of Iphigenia in the Trojan War and Penelope in the Odyssey).

(7) A comparative view of different cultures and societies that gave birth to myths, and identifying differences and similarities within the framework of an intercultural approach (for example, ecumenical symbols and universal values, such as earth goddess and fertility, virtue, fairness as a hero's attribute).

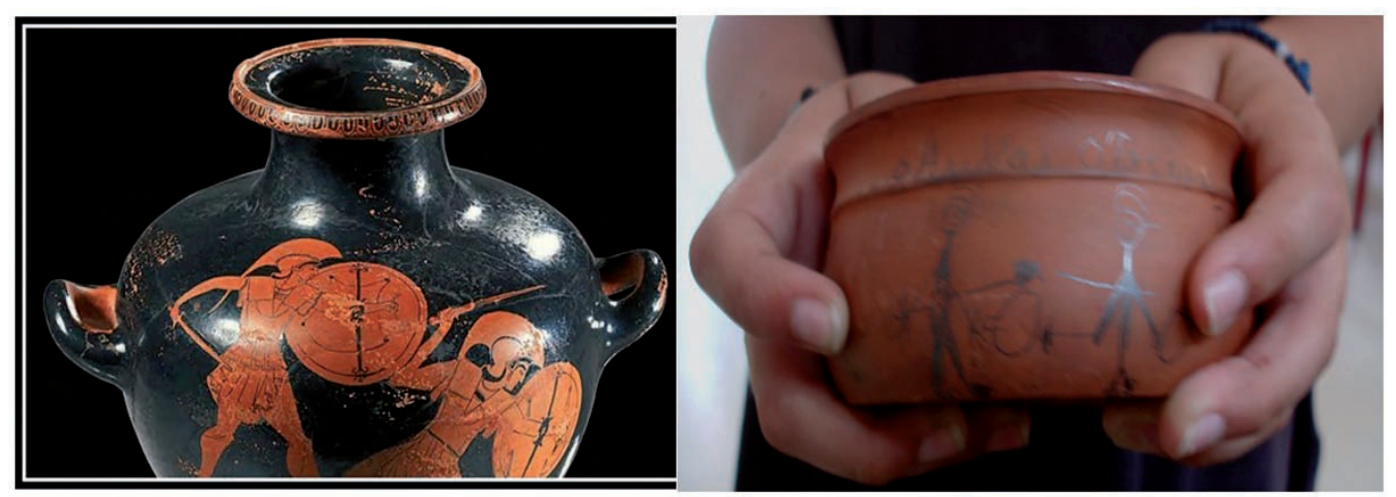

Figure 3: Reading myths represented on pottery

\section{Analysing the data}

A content analysis of the pupils' answers was carried out. Answers were examined in relation to the following discrete variables:

(1) the class attended by the pupils

(2) gender

(3) their family's cultural capital.

The following findings were recorded during the analysis.

\section{The class attended by the pupils}

With regard to the first variable, the class attended by the pupils, almost all pupils in the first class believe that the Trojan War was a fact and not a myth. They attribute its causes to the development of trade and the quest for riches: 'Troy was a rich city. The Achaeans went there to get gold'; 'Troy was in a good location'; 'The Trojan War is a fact, because they practised trade and Troy was a very good port'. The pupils in the first group were acquainted with the terms 'allegorical' and 'symbolic', and were encouraged, through relevant questions, to make assumptions about the meaning of the myths and to discern the motives of the heroes/actors.

In the pupils' answers from the control group, usually only the mythical version is presented: 'The War happened because Paris took beautiful Helen'. Similarly, the reasons are not clear: 'In my opinion, the Trojan War was a major event, because many people died in Troy'. In addition, according to the answers of several pupils from the second group, mythology is only related to the imaginary and is the opposite of reality and rational events: A pupil answered: 'The Trojan War happened in Mythology because of the kidnapping of beautiful Helen. Reality: The Trojan War happened, because Troy was a very rich country, which is why the Achaeans wanted to conquer it'. This opposition reveals: 'The bias regarding the understanding of ancient Greek myths: the antithesis between the myths and pure rational forms of expression, philosophy and historiography' (Karakantza, 2004: 35). There were also pupils in both the first and 
second groups whose answers combine mythical and historical facts: 'The Trojan War happened so that the Achaeans could take back beautiful Helen, because Paris stole her and took her to Troy, a rich country in Asia Minor'. Those pupils ascertain what Nestle (1999: 21) refers to as 'the interpenetration of Logos and Mythos'.

Regarding the role models projected in myths, a higher number of pupils in the first group attempted to pass judgement on the social and cultural framework, in which the relevant actions or mythological conceptualization of people is included: 'The sacrifice of Iphigenia happened because the position of women in ancient Greece was not so good'; 'Women were not important then'. Pupils were invited to compare the position of different women in various myths, taking into consideration the customs of the societies in which they lived, and to identify common attitudes and roles (for example, the cases of Iphigenia in the Trojan War and Penelope in the Odyssey). Furthermore, pupils were asked to represent the customs that were highlighted through role-play.

Among the pupils in the control group, there is a higher frequency of actions being projected into the present, and a greater use of modern criteria for making judgements. The past and present fuse into an almost eternal time frame. It is a version of presentism over historicity. The pupils in the control group did not understand the different customs of the specific society, according to which women are underestimated and considered inferior to men. Their empathy is quite reasonable in present-day terms (Portal, 1987; Lee and Ashby, 2001). A pupil characteristically observes: 'In my opinion, Iphigenia's sacrifice was harsh. Agamemnon's decision was not right'; 'The sacrifice was unjust, because men and women have the same rights in our day and age'.

The comparison with modern role models and heroes allows for a reinterpretation of the mythical hero and the enhancement of attributes that are related to his/her character, such as: 'love for his fellow humans, the pursuit of justice, supporting those in need (for example, Theseus)'. Similarly, the attributes of ancient Greek heroes are sought in modern people, such as lifeguards, soldiers and firefighters, who 'take risks and sacrifice their life for their fellow human beings'. However, several children in the first group express their concern about using the term 'hero', and accordingly conveying the model behaviour of the mythical hero to the modern age. They write, for example: 'There are no heroes any more like there used to be'; 'There are no heroes in our day and age'; 'Firefighters are not exactly heroes, but they are like heroes'. Moreover, they do not mention the names of specific people.

The pupils in the control group mention specific superheroes from animated and fiction films, and attributes, such as 'physical strength' and 'protecting people from evil'. They often use the past tense as though the hero was a real person: 'Batman saved the world from a lot of bad people'. When correlating myths to the interpretation of natural phenomena (in the question referring to Scylla and Charybdis), the pupils in the first group assume that these 'sea monsters' were probably used to explain phenomena of the sea, such as 'storms, whirlpools, tsunamis, tidal waves'. They justify their shapes that feature 'snakes' heads, terrifying faces' by using the argument that the ancient Greeks feared them, which is why they presented them in such a way. This is a collective negative feeling that is transferred to the myth (Caldwell, 1990). All the pupils in the first group make assumptions and attempt to explain the myths by trying to reveal their underlying meaning.

The pupils in the control group stated that Scylla and Charybdis were sea monsters, and that such creatures were quite common in ancient times. They connected them to a primitive but inferior past. 


\section{Gender}

As far as the gender variable is concerned, it was noted that pupils of the same gender as the hero were more prone to identify with him/her, and consequently to transfer actions to the present and evaluate actions using 'presentist' criteria. More specifically, although the lliad praises the glory of men, the girls in the control group discern a heroine in the form of Iphigenia, who is a rare role model in the myths that were narrated: 'Iphigenia is brave, because she is not afraid to die'. Furthermore, when the girls in the control group were asked which mythical hero they would like to be, they chose females, either a mortal or a goddess. Boys of the same group justify their choice of male heroes because of their strength and courage.

When girls of the first group were asked which mythical hero they would like to be, they most frequently referred to male heroes, since they had understood by developing cultural empathy that this is the role model of the hero in ancient Greek society. In fact, girls of the first group justify their choice by referring to the mental state of the hero and not his vigour. They often choose Ulysses: 'I would like to be Ulysses, because it was his wit that got them into Troy'; 'The best hero is Ulysses, because he made plans and he was smart and creative'.

In contrast, the role models chosen by the boys of the first group include properties that are mainly related to a hero's physical strength (powerful, brave, fearless). The same attributes are also noted by the pupils when Hector gives advice to his son Astyanax before his clash with Achilles (Homer, Iliad VII, v. 474-81). These attributes are also stereotypically repeated as a kind of motif for the description of various heroes (Achilles, Theseus, Ulysses). According to Benoist (1992):

In myths, the main actors may change, but the way they are used remains the same. And if the hero of the ritual can be replaced by another, on each occasion, the myth imposes the role model that is often hidden under the fictional.

\section{Their family's cultural capital}

When examining the third variable, that is, the family's cultural capital (specific experiences, knowledge and religious beliefs, due to their diverse social, ethnocultural and religious identities), it was noted that the pupils in the first group tended to convey specific knowledge from their own family environment and proceed with their own assumptions and interpretations. More specifically, one pupil noted: 'Scylla and Charybdis did not actually exist. There was simply a lot of major "turbulence" in those waters that they could not explain'.

Similarly, in the myth that describes the way in which Heracles cleaned the stables of Augeas, pupils from families who were involved in agricultural and technical professions understood the way in which the hero used the water. They described his labour by using expressions such as channels (avlakia), pipes (agogoi) and diversion. Figure 4 is a drawing by a pupil showing that Heracles washed out Augeas's stables by changing the route of two rivers. 


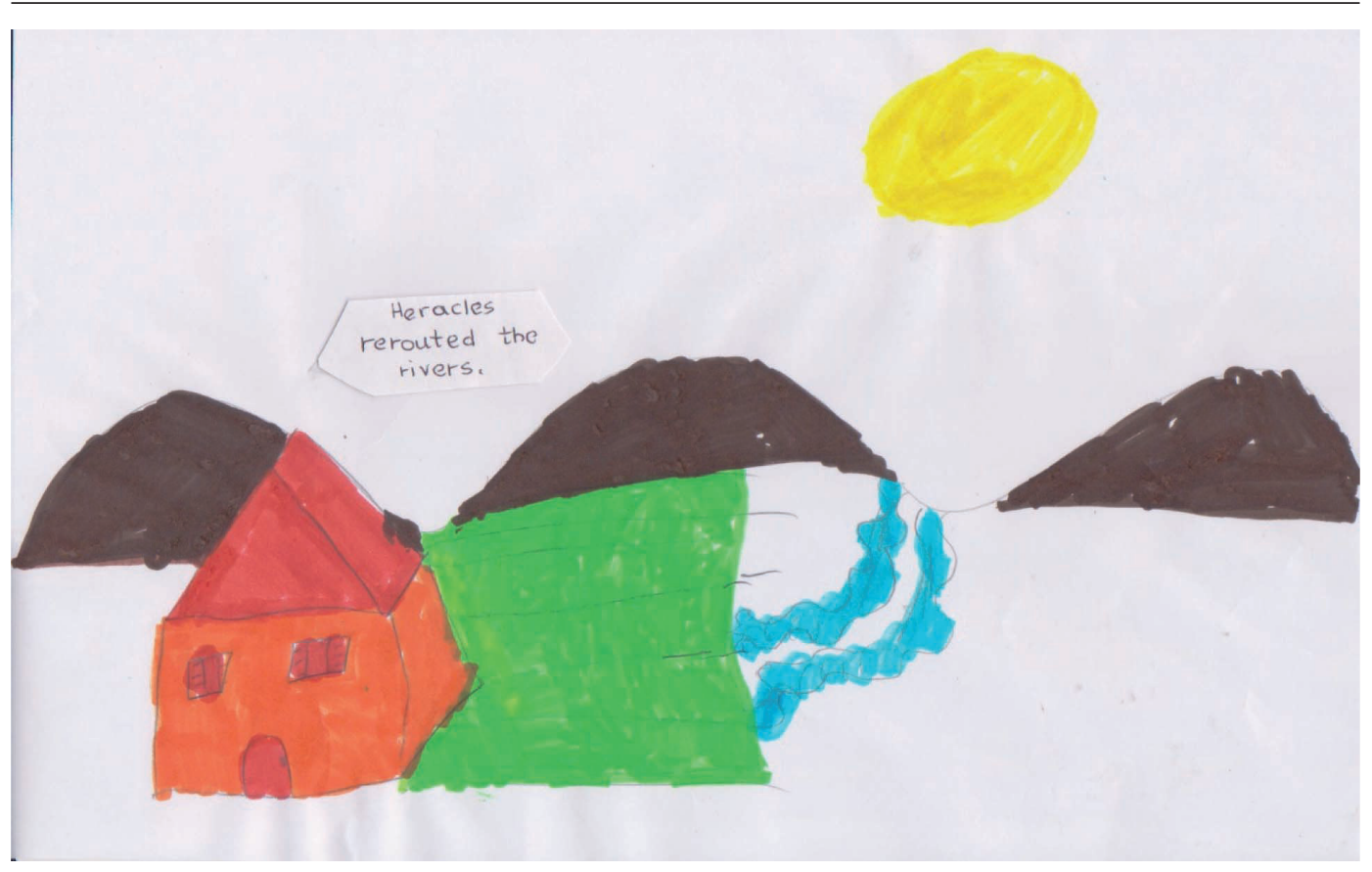

Figure 4: Child's drawing - Hercules rerouted the rivers Alpheus and Peneus to wash out Augeas's stables

Similarly, when Ulysses descends to Hades, the Underworld is connected to certain representations and becomes the pretext for the promotion of religious traditions and views about life and death. More specifically, a pupil mentions that 'There is darkness everywhere and silence, and the dead are resting'. There were also pupils who noted that: 'The Underworld is deep below the earth and only bad people go there' and also 'it is a place for lost souls'. Moreover, some pupils said that 'People die and are born on earth', implying that there is a continuous life cycle.

Furthermore, pupils of the first group were acquainted with the meaning of terms such as 'mystery' or 'miracle'. For instance, the sacrifice of Iphigenia was perceived as an unexplained mystery and, as such, does not in fact signify the loss of life. As a pupil noted: 'It is not a sacrifice, because a miracle happens in the end and she is saved at the last minute by Artemis'. According to Benoist (1992: 116), some religious rituals and sacraments have allowed for the transfer of a spiritual influence in the past and in the present that can facilitate a metaphysical actualization.

\section{Conclusion}

The experimental implementation of the new curriculum demonstrates that myth can help to develop historical concepts and can nurture the critical skills of historical empathy and imagination. The pupils who participated in the applied activities according to the new history curriculum for the third grade examined the causes of, and the historical truth found in, myths. They correlated myths with the interpretation of natural phenomena and the environment in which changes are observed. In addition, they perceived that mythos goes hand in hand with logos and the reverse.

Myths can acquaint pupils with cultural differences and contribute to the enrichment of pupils' schemata. The pupils who participated in the proposed activities discerned the values that govern the behaviour of the main actors, and the specific moral standards formulated within the relevant historical and cultural framework. They 
also had a comparative view of the present and the past, by examining the different motives, causes and consequences of the actors' actions. Pupils developed cultural empathy and learned about the differences and similarities that exist among different cultures, religions and societies, which gave birth to myths within the framework of an intercultural approach.

The applied educational activities are based on a more learner-centred approach. Pupils are encouraged to participate and express their own views on the meaning of myths in creative ways. This proved to be a really effective practice, especially for pupils from different cultural backgrounds. The experimental implementation of the educational activities described also proved that pupils of this age can develop important historical skills, such as the formulation of alternative interpretations and assumptions regarding the 'allegorical' features of the myths in particular, and the comparative use of various historical sources.

According to this approach to mythology, children are familiarized with the cultural grammar of the origins of Greek, European and global civilization. Furthermore, they realize that myths refer to rituals and customs, which subsequently answer to social needs and express social processes. They observe that myths also function as mechanisms for the internalization and reproduction of relations and values, especially for the younger members of a society, and subsequently lead to its cohesion.

To conclude, the proposed perspective includes two predominant axes found in myths:

(1) the search for the primary cause of life (metaphysical focus)

(2) the principles that govern our behaviour (moral focus). (Diel, 1980: 22)

According to Benoist (1992: 138-9):

When we have been initiated into a system of points that can be understood, and when we have the ability, like Orpheus, to set our song free, then [we will know full well] that this settlement of points, this alphabet of symbols and rituals, is what defines a civilization.

Through the proposal we have described, we defend the fascination of a journey in search of mythical creatures and historical facts, in order to decipher the symbolism hidden within the traces of physical necessity, historical purpose and distinct cultural routes.

\section{Notes on the contributors}

Maria Vlachaki has a PhD in oral history and history education and postgraduate degrees in museology and intercultural education. She works as a primary school head teacher and as an adjunct lecturer at the University of Thessaly. She cooperated in the development of the history curriculum for elementary school education in Greece.

George Kokkinos is Professor of History and History Didactics at the University of the

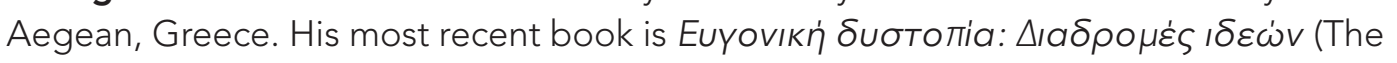
Dystopia of Eugenics: Trajectories of ideas), published in 2018 by Thines.

Zeta Papandreou has a PhD in history education and works as an adjunct lecturer in the Department of Primary Education in the University of the Aegean. She is doing postdoctorate research in the National Technical University of Athens, Department of Architecture - School of Engineering. Her research interests include teaching of traumatic historical events (World War II and the German occupation of Greece), as well as the theory of history education. 


\section{References}

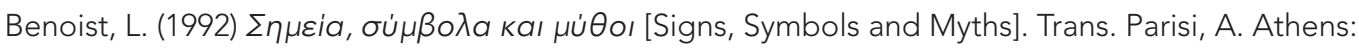
A. Kardamitsa.

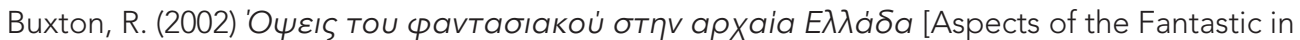
Ancient Greece]. Trans. Tyflopoulos, T. Thessaloniki: University Studio Press.

Caldwell, R. (1990) 'The psychoanalytic interpretation of Greek myth'. In Edmunds, L. (ed.) Approaches to Greek Myth. Baltimore: Johns Hopkins University Press, 342-89.

Council of Europe (2018) Quality History Education in the 21st Century: Principles and guidelines. Strasbourg: Council of Europe. Online. https://tinyurl.com/y3qepwwl (accessed 6 July 2019).

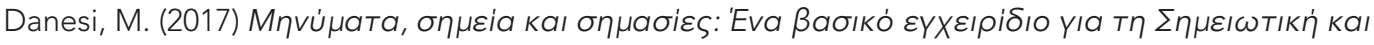

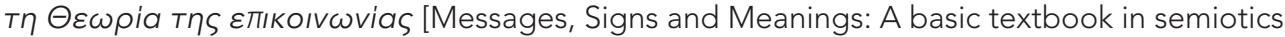
and communication theory]. Ed. Dalkavoukis, V. Trans. Kokkinou, H. Thessaloniki: University Studio Press.

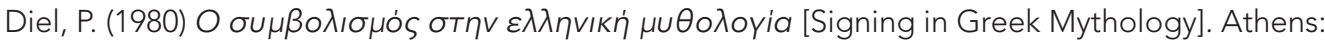
Chatzinikoli.

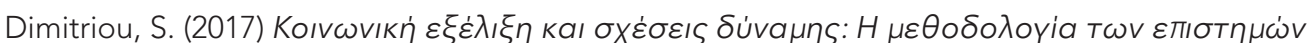
тоu av $\theta \rho \omega$ กтоu [Social Evolution and Power Relations: The methodology of human sciences]. Athens: Alexandria Editions.

Egan, K. (1986) Teaching as Story-telling: An alternative approach to teaching and curriculum in the elementary school. Chicago: University of Chicago Press.

Ellis, A.K. (2010) Teaching and Learning Elementary Social Studies. 9th ed. Boston: Pearson.

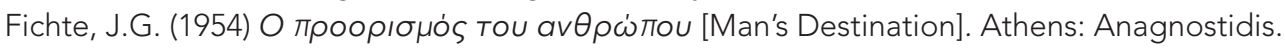

Fines, J. (2002) 'Letting the past speak'. International Journal of Historical Learning, Teaching and Research, 2 (2), 5-137.

Freud, S. (1991) The Standard Edition of the Complete Psychological Works of Sigmund Freud: Volume 4: The interpretation of dreams. London: Hogarth Press.

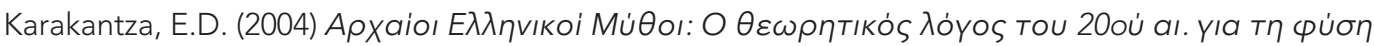

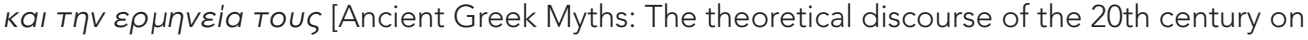
their nature and interpretation]. Athens: Metaichmio.

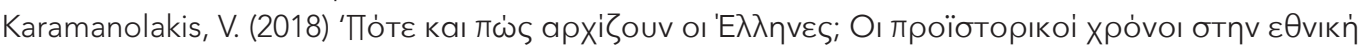

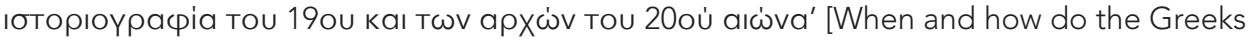
begin? The prehistoric times in the national historiography of the 19th and early 20th century]. In Katsiardi-Hering, O., Papadia-Lala, A., Nikolaou, K. and Karamanolakis, V. (eds) Hellene, Romios, Greek: Collective identifications and identities (Historimata 7). Athens: Evrasia.

Kirk, G.S. (1974) The Nature of Greek Myths. Harmondsworth: Penguin Books.

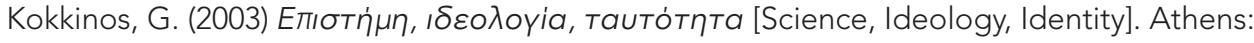
Metaichmio.

Koselleck, R., Lutz, H. and Rüsen, J. (eds) (1982) Formen der Geschichtsschreibung: Theorie der Geschichte (Beiträge zur Historik 4). München: Deutscher Taschenbuch Verlag.

Lang, A. (1887) Myth, Ritual, and Religion. Online. https://tinyurl.com/y3bb9tfb (accessed 6 July 2019).

Lee, P. and Ashby, R. (2001) 'Empathy, perspective taking, and rational understanding'. In Davis, O.L., Yeager, E.A. and Foster, S.J. (eds) Historical Empathy and Perspective Taking in the Social Studies. Lanham, MD: Rowman and Littlefield, 21-50.

Lévi-Strauss, C. (1963) Structural Anthropology. Trans. Jacobson, C. and Grundfest Schoepf, B. New York: Basic Books.

Lévi-Strauss, C. (1978) Myth and Meaning (The 1977 Massey Lectures). London: Routledge and Kegan Paul.

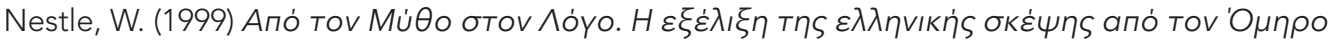

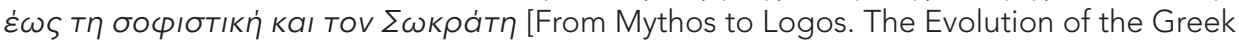
Thought from Homer to Sophistry and Socrates]. Athens: Gnosi.

Portal, C. (1987) 'Empathy as an objective for history teaching'. In Portal, C. (ed.) The History Curriculum for Teachers. London: Falmer Press, 89-99.

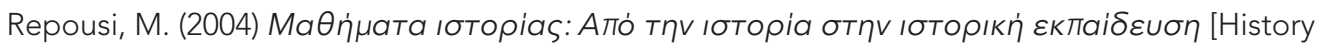
Courses: From history to historical education]. Athens: Kastanioti.

Rowley, C. and Cooper, H. (eds) (2009) Cross-Curricular Approaches to Teaching and Learning. London: SAGE Publications. 
Solé, G., Reis, D. and Machado, A. (2016) 'The potentialities of using historical fiction and legends in history teaching: A study with primary education Portuguese students'. International Journal of Historical Learning, Teaching and Research, 14 (1), 137-54.

Stevens, A. (2006) 'The archetypes'. In Papadopoulos, R.K. (ed.) The Handbook of Jungian Psychology: Theory, practice and applications. London: Routledge, 74-93.

Vernant, J.-P. (2001) The Universe, the Gods, and Men: Ancient Greek myths. Trans. Asher, L. New York: HarperCollins.

Wertsch, J.V. (2002) Voices of Collective Remembering. Cambridge: Cambridge University Press. 